\title{
Effect of the Conservation Procedure on the Contents of Phenolic Compounds and Organic Acids in Chanterelle (Cantharellus cibarius) Mushroom
}

\author{
Patrícia Valentão, ${ }^{\dagger}$ Paula B. Andrade,${ }^{\dagger}$ Joana Rangel,${ }^{\dagger}$ \\ Bárbara Ribeiro ${ }^{\dagger}$ Branca M. Silva ${ }^{\dagger}$ Paula BaPtista,$\ddagger$ AND \\ Rosa M. SEABRA*,†
}

REQUIMTE/Serviço de Farmacognosia, Faculdade de Farmácia, Universidade do Porto, R. Aníbal Cunha 164, 4050-047 Porto, Portugal, and CIMO/ESAB, Quinta de Sta Apolónia, Apartado 1172, 5301-855 Bragança, Portugal

\begin{abstract}
To check the influence of the conservation procedure in the chemical composition of chanterelle mushroom, phenolic compounds and organic acids of samples preserved under four different conditions (drying, freezing, conservation in olive oil and in vinegar) were determined. Phenolics and organic acids were analyzed by HPLC-DAD and HPLC-UV, respectively. The results showed that chanterelle is characterized by the presence of six phenolic compounds (3-, 4-, and 5-O-caffeoylquinic acid, caffeic acid, p-coumaric acid, and rutin) and five organic acids (citric, ascorbic, malic, shikimic, and fumaric acids). Samples preserved in olive oil also exhibited hydroxytyrosol, tyrosol, luteolin, and apigenin, whereas conservation in vinegar led to the detection of hydroxytyrosol, tyrosol, and tartaric acid in the analyzed samples. The conservation procedures to which chanterelle samples were subjected seem to affect the qualitative and quantitative phenolics and organic acids profiles.
\end{abstract}

KEYWORDS: Chanterelle; Cantharellus cibarius; conservation; phenolic compounds; organic acids

\section{INTRODUCTION}

In recent years an increase in the consumption of wild edible mushrooms has been observed, even in the developed world, although they do not constitute a significant portion of the human diet. In fact, wild-growing mushrooms have been a popular delicacy in many countries, mainly in central and eastern Europe $(1-3)$, as they add flavor and texture to a meal (4).

Previous studies have indicated that edible mushroom species are highly nutritious, their nutritional value comparing favorably with that of meat, eggs, and milk (5). They present a good balance of vitamins, namely, thiamin, riboflavin, ascorbic acid, and vitamin $\mathrm{D}_{2}$ and a good content of proteins as well as a high content of trace minerals. They are poor in calories and fat and contain appreciable amounts of dietary fiber $(3,6-8)$. However, the nutritional characteristics can be changed by the cultivation, watering, fruiting, and storage conditions, which influence their chemical composition $(7,8)$.

Edible mushrooms are characterized by a short shelf life (1-3 days at room temperature), linked to the occurrence of postharvest changes. These changes are due to the high moisture content of the carpophores and the high activity of enzymes,

* Author to whom correspondence should be addressed (telephone + 351 222078934; fax + 351 222003977; e-mail rseabra@ff.up.pt).

REQUIMTE.

$\doteqdot \mathrm{CIMO} / \mathrm{ESAB}$ such as protease or polyphenol oxidase, responsible for protein and sugar decrease and for browning reactions during storage (9).

The chanterelle (Cantharellus cibarius) is an edible mushroom with a worldwide distribution, fruiting from fall to early spring. It is highly appreciated for its wonderful fruity, apricotlike aroma, being particularly prized for cooking throughout Europe. Besides the flavor and smell, its texture is also nice. The chanterelle is of great economical interest for northeastern Portugal, because its collection constitutes a way of subsistence for the residents, apart from becoming an important commercial source.

Previous studies on the chanterelle concerned its amino acids (5), vitamin D $(10,11)$, protein $(3,12)$, fat (3), fiber (3), ash $(3,12)$, minerals $(2,3,12,13)$, ascorbic acid $(3)$, and trace elements contents (1), the characterization of basidiolipids (14), a ubiquitin-like peptide (15), and a homodimeric laccase (16), the use of different nitrogen sources (17), the production of bioactive secondary metabolites (18), and the biological activities of two fatty acid derivatives formed as a response to injury (19), and its mutagenic (20) and insecticidal properties (21). As far as we know, nothing as been reported about the phenolics and organic acids profile of the chanterelle.

Phenolic compounds and organic acids are known to contribute to the organoleptic characteristics of fruits and vegetables (4). Additionally, these compounds may have a protective role against various diseases due to their antioxidant activity (22). 
Table 1. Chanterelle Sample Treatment

\begin{tabular}{clcc}
\hline sample & conservation procedure & sample & conservation procedure \\
\hline 1 & drying at $30^{\circ} \mathrm{C}$ for $96 \mathrm{~h}$ & 7 & in vinegar \\
2 & drying at $30^{\circ} \mathrm{C}$ for $96 \mathrm{~h}$ & 8 & in vinegar \\
3 & drying at $30^{\circ} \mathrm{C}$ for $96 \mathrm{~h}$ & 9 & in vinegar \\
4 & freezing & 10 & in olive oil \\
5 & freezing & 11 & in olive oil \\
6 & freezing & & \\
\hline
\end{tabular}

The main purposes of this study were to determine the phenolic compounds and organic acids composition of chanterelle and to investigate the influence of the conservation process in these chemical parameters. With this aim, chanterelle samples subjected to four different preservation procedures (drying, freezing, and conservation in olive oil and in vinegar) were analyzed.

\section{MATERIALS AND METHODS}

Samples. Samples of chanterelle were collected from a chestnut orchard (Castanea sativa Mill.) in the Bragança region (northeastern Portugal), in the spring of 2004. After collection, the mushrooms were immediately transferred to the laboratory. Taxonomic identification followed that of several authors $(23-28)$. Representative voucher specimens were deposited at the herbarium of Escola Superior Agrária of Instituto Politécnico de Bragança.

Samples were preserved under four distinct methods commonly used for the commercialization of the chanterelle (Table 1). Samples 1-3 were dehydrated in a ventilated stove at $30{ }^{\circ} \mathrm{C}$ for 4 days. They were kept in the dark, in hermetically sealed plastic bags. Frozen samples (samples 4-6) were previously cleaned and boiled in water with salt during $2 \mathrm{~min}$; after being dried with absorbent paper, they were placed in plastic bags, which were then quickly frozen in a freezer at $-20^{\circ} \mathrm{C}$. Samples 7-9 were preserved in vinegar, as pickles: the mushrooms were cleaned and boiled in water with salt for $15 \mathrm{~min}$; after being dried with absorbent paper, they were placed in flasks, which were filled with white wine vinegar with a little sugar and hermetically closed. Samples preserved in olive oil (samples 10 and 11) were boiled for 10 min in a mixture of $250 \mathrm{~mL}$ of white wine vinegar and $150 \mathrm{~mL}$ of water with salt; after being dried with absorbent paper, they were placed in flasks, which were filled with olive oil (extra virgin quality) and hermetically closed. All of the samples were kept for 4 months under the conditions described above until analysis.

Before analysis, samples 7-11 were cleaned with absorbent paper for the removal of vinegar and olive oil and frozen. With the exception of those subjected to the drying process (samples 1-3), all of the analyzed samples were freeze-dried in a Labconco 4.5 apparatus (Kansas City, MO), yielding 10\% of dry matter.

Standards. The standards were from Sigma (St. Louis, MO) and from Extrasynthése (Genay, France). Methanol and formic and hydrochloric acids were obtained from Merck (Darmstadt, Germany), and sulfuric acid was from Pronalab (Lisboa, Portugal). The water was treated in a Milli-Q water purification system (Millipore, Bedford, MA).

Solid-Phase Extraction (SPE) Columns. The ISOLUTE C18 nonend-capped (NEC) SPE columns (50 $\mu \mathrm{m}$ particle size, $60 \AA$ porosity; $10 \mathrm{~g}$ sorbent mass $/ 70 \mathrm{~mL}$ reservoir volume) were purchased from International Sorbent Technology Ltd. (Mid Glamorgan, U.K.).

Extraction of Phenolics and Organic Acids. Each mushroom sample $(\sim 1 \mathrm{~g})$ was thoroughly mixed with methanol $(5 \times 50 \mathrm{~mL})$, at $40{ }^{\circ} \mathrm{C}$. The methanolic extract was filtered and concentrated to dryness under reduced pressure $\left(40{ }^{\circ} \mathrm{C}\right)$.

The organic acids fractions were obtained according to a described procedure (29). The residue of the methanolic extract was redissolved in acid water ( $\mathrm{pH} 2$ with $\mathrm{HCl})(\sim 50 \mathrm{~mL})$, and the aqueous solution was then passed through an ISOLUTE C18 (NEC) column, previously conditioned with $30 \mathrm{~mL}$ of methanol and $70 \mathrm{~mL}$ of acid water $(\mathrm{pH} 2$ with $\mathrm{HCl}$ ). The aqueous extract, containing the organic acids, was evaporated to dryness under reduced pressure $\left(40{ }^{\circ} \mathrm{C}\right)$ and redissolved in $0.01 \mathrm{~N}$ sulfuric acid $(1 \mathrm{~mL})$, and $20 \mu \mathrm{L}$ was analyzed by HPLCUV.
After the elution of organic acids and other polar compounds with the aqueous solvent, the retained phenolic fraction was eluted with methanol $(\sim 150 \mathrm{~mL})$. The extracts were concentrated to dryness under reduced pressure $\left(40{ }^{\circ} \mathrm{C}\right)$ and redissolved in methanol $(1 \mathrm{~mL})$, and 20 $\mu \mathrm{L}$ was analyzed by HPLC-DAD.

HPLC Analysis of Organic Acids. The separation was carried out as previously reported (29) with an analytical HPLC unit (Gilson), using an ion exclusion Nucleogel Ion $300 \mathrm{OA}(300 \times 7.7 \mathrm{~mm})$ column, in conjunction with a column heating device at $30^{\circ} \mathrm{C}$. Elution was carried out at a solvent flow rate of $0.1 \mathrm{~mL} / \mathrm{min}$, isocratically, with $0.01 \mathrm{~N}$ sulfuric acid as the mobile phase. Detection was performed with a UV detector set at $214 \mathrm{~nm}$.

Organic acids quantification was achieved by the absorbance recorded in the chromatograms relative to external standards.

HPLC Analysis of Phenolics. The extracts were analyzed on an analytical HPLC unit (Gilson), using a Spherisorb ODS2 $(25.0 \times 0.46$ $\mathrm{cm} ; 5 \mu \mathrm{m}$, particle size) column (30-34). The solvent system used was a gradient of water/formic acid (19:1) (A) and methanol (B), starting with $5 \%$ methanol and installing a gradient to obtain $15 \% \mathrm{~B}$ at $3 \mathrm{~min}, 25 \% \mathrm{~B}$ at $13 \mathrm{~min}, 30 \% \mathrm{~B}$ at $25 \mathrm{~min}, 35 \% \mathrm{~B}$ at $35 \mathrm{~min}, 45 \% \mathrm{~B}$ at $39 \mathrm{~min}, 45 \% \mathrm{~B}$ at $42 \mathrm{~min}, 50 \% \mathrm{~B}$ at $44 \mathrm{~min}, 55 \% \mathrm{~B}$ at $47 \mathrm{~min}, 70 \%$ $\mathrm{B}$ at $50 \mathrm{~min}, 75 \% \mathrm{~B}$ at $56 \mathrm{~min}$, and $80 \% \mathrm{~B}$ at $60 \mathrm{~min}$, at a solvent flow rate of $0.9 \mathrm{~mL} / \mathrm{min}$. Detection was achieved with a Gilson diode array detector. The compounds in each sample were identified by comparing their retention times and UV-vis spectra in the 200-400 nm range with the library of spectra previously compiled by the authors. Peak purity was checked by means of the Gilson 160 SpectraViewer Software Contrast Facilities.

Phenolic compounds quantification was achieved by the absorbance recorded in the chromatograms relative to external standards, at 280 $\mathrm{nm}$ for hydroxytyrosol and tyrosol, at $320 \mathrm{~nm}$ for phenolic acids, and at $350 \mathrm{~nm}$ for flavonoids. 3- and 4-O-caffeoylquinic acids were quantified as 5-O-caffeoylquinic acid, and hydroxytyrosol was quantified as tyrosol. The other compounds were quantified as themselves.

Statistical Analysis. The evaluation of statistical significance was determined by ANOVA, followed by Newman-Keuls test. The level of significance was set at $p<0.05$.

\section{RESULTS AND DISCUSSION}

Mushroom browning is a major biochemical event after harvest. It is one of the main features, besides texture and cap opening, considered in the quality spectrum. Mushrooms are praised for their characteristic biting texture and pleasant flavor; however, one or both of these properties are lost during mushroom processing (35). In addition, it is known that the storage conditions can influence the chemical composition and, as a consequence, the nutritional value of mushrooms (7).

Chanterelle is an edible mushroom species very appreciated in Europe, used in several cookery preparations. Because of its great consumption, data on its nutritional value are needed. Therefore, this work was developed for the identification and quantification of the phenolic compounds and organic acids of this species and the evaluation of the influence of the conservation procedure in these chemical parameters.

Phenolic Compounds. The analysis of chanterelle frozen samples (samples 4-6) by reversed-phase HPLC-DAD allowed the identification of six phenolic compounds in this species (Figure 1): 3-, 4-, and 5-O-caffeoylquinic acids, caffeic acid, $p$-coumaric acid, and rutin. Despite these compounds, several unidentified flavonoids were also noted. On a quantitative level, chanterelle has very low amounts of phenolic compounds $(\sim 20.0$ $\mathrm{mg} / \mathrm{kg}$ ) (Table 2), 3-O-caffeoylquinic acid being the main compound (64\% of total identified phenolics) (Figure 3). It should be noted that the deep-freezing process represents a common way to increase storage stability and facilitate mushroom consumption without seasonal constraints (9). 


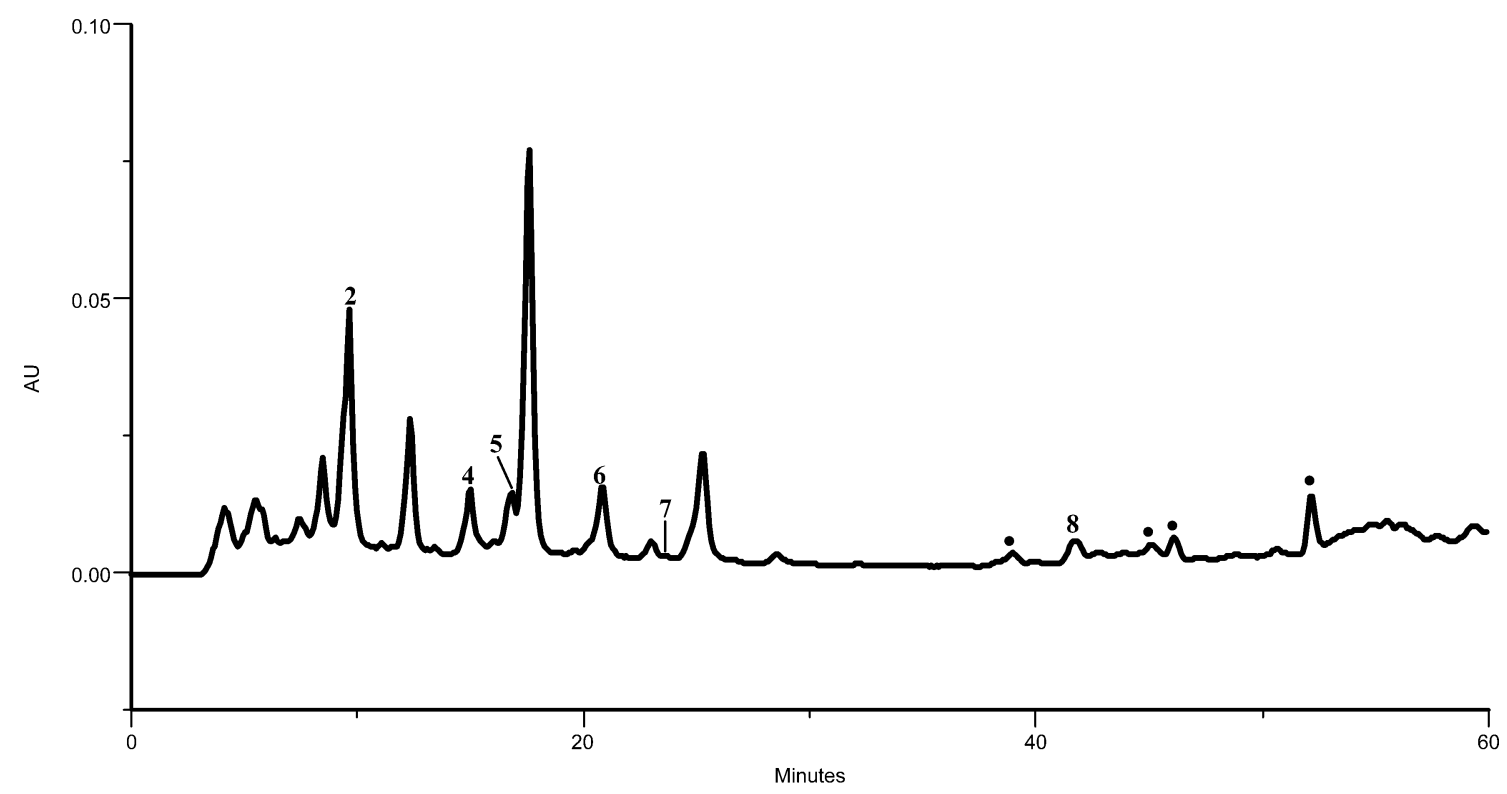

Figure 1. HPLC-DAD chromatogram of phenolic compounds in chanterelle (frozen sample). Detection was at $320 \mathrm{~nm}$. Peaks: (2) 3-0-caffeoylquinic acid; (4) 4-O-caffeoylquinic acid; (5) 5-O-caffeoylquinic acid; (6) caffeic acid; (7) p-coumaric acid; (8) rutin; (๑) unidentified flavonoids.

Table 2. Phenolics Composition of Chanterelle ${ }^{a}$

\begin{tabular}{|c|c|c|c|c|c|c|c|c|c|c|c|}
\hline \multirow[b]{2}{*}{ sample } & \multicolumn{10}{|c|}{ compound (mg/kg, dry basis) } & \multirow[b]{2}{*}{ total } \\
\hline & $\begin{array}{l}\text { hydroxy- } \\
\text { tyrosol }\end{array}$ & $\begin{array}{l}\text { 3-O-caffeoyl- } \\
\text { quinic acid }\end{array}$ & tyrosol & $\begin{array}{l}\text { 4-O-caffeoyl- } \\
\text { quinic acid }\end{array}$ & $\begin{array}{l}\text { 5-O-caffeoyl- } \\
\text { quinic acid }\end{array}$ & caffeic acid & $\begin{array}{l}p \text {-coumaric } \\
\text { acid }\end{array}$ & rutin & luteolin & apigenin & \\
\hline 1 & & $2.3(0.2)$ & & $0.4(0.0)$ & & $4.2(0.0)$ & $\mathrm{nq}$ & $0.8(0.1)$ & & & 7.8 \\
\hline 2 & & $18.2(0.4)$ & & $\mathrm{nq}$ & $1.8(0.2)$ & $2.0(0.1)$ & $1.6(0.0)$ & $0.8(0.1)$ & & & 24.4 \\
\hline 3 & & $11.1(0.3)$ & & $\mathrm{nq}$ & $0.7(0.2)$ & $1.5(0.1)$ & $0.5(0.0)$ & $0.4(0.1)$ & & & 14.2 \\
\hline 4 & & $11.6(0.1)$ & & $2.6(0.1)$ & $2.7(0.0)$ & $1.9(0.1)$ & $0.3(0.1)$ & $1.8(0.0)$ & & & 21.0 \\
\hline 5 & & $20.0(0.8)$ & & $1.2(0.1)$ & $2.3(0.8)$ & $1.1(0.0)$ & $\mathrm{ng}$ & $0.9(0.1)$ & & & 25.4 \\
\hline 6 & & $8.1(1.5)$ & & $1.1(0.2)$ & $2.4(0.2)$ & $0.9(0.1)$ & $0.4(0.3)$ & $0.7(0.1)$ & & & 13.6 \\
\hline 7 & $305.5(8.8)$ & & $46.9(1.8)$ & $\mathrm{nq}$ & $\mathrm{nq}$ & $\mathrm{nq}$ & $\mathrm{nq}$ & $5.0(0.1)$ & & & 357.4 \\
\hline 8 & $210.9(3.1)$ & & $35.4(0.6)$ & $\mathrm{nq}$ & nq & $\mathrm{nq}$ & $\mathrm{nq}$ & $\mathrm{nq}$ & & & 246.3 \\
\hline 9 & 359.4 (22.1) & & $52.8(1.9)$ & $\mathrm{nq}$ & $1.6(0.7)$ & $\mathrm{nq}$ & $\mathrm{ng}$ & $0.7(0.1)$ & & & 414.4 \\
\hline 10 & $349.4(22.6)$ & & $349.0(6.6)$ & & & $0.9(0.0)$ & $2.6(0.1)$ & $1.8(0.1)$ & $88.4(3.9)$ & $14.4(1.2)$ & 806.5 \\
\hline 11 & $437.4(37.9)$ & & $450.1(10.0)$ & & & $0.3(0.0)$ & $3.2(0.3)$ & $12.3(0.5)$ & $75.8(10.3)$ & $15.4(1.9)$ & 994.4 \\
\hline
\end{tabular}

${ }^{\text {a }}$ Results are expressed as mean (standard deviation) of three determinations. nq, not quantified.

Table 3. Organic Acids Composition of Chanterelle ${ }^{a}$

\begin{tabular}{|c|c|c|c|c|c|c|}
\hline \multirow[b]{2}{*}{ sample } & \multicolumn{5}{|c|}{ compound (mg/kg, dry basis) } & \multirow[b]{2}{*}{ total } \\
\hline & citric acid & ascorbic acid & malic acid & shikimic acid & fumaric acid & \\
\hline 1 & $696.9(1.3)$ & $187.3(14.9)$ & $4500.1(26.8)$ & $0.9(0.1)$ & $0.4(0.1)$ & 5385.6 \\
\hline 2 & $26.3(0.6)$ & $19.3(0.9)$ & $178.5(10.0)$ & & $5.0(0.0)$ & 229.1 \\
\hline 3 & $881.3(4.5)$ & nq & $2641.3(35.1)$ & & $36.1(0.5)$ & 3559.5 \\
\hline 4 & $1384.1(95.6)$ & $\mathrm{ng}$ & 6999.9 (1042.1) & $0.4(0.1)$ & $44.5(2.8)$ & 8428.9 \\
\hline 5 & $1140.1(27.1)$ & $\mathrm{nq}$ & $4229.0(24.8)$ & $0.2(0.0)$ & $41.2(0.6)$ & 5410.5 \\
\hline 6 & $283.7(5.0)$ & $33.1(10.3)$ & $4239.1(7.8)$ & $\mathrm{nq}$ & $1.2(1.3)$ & 4557.1 \\
\hline 7 & $135.5(0.6)$ & $7865.4(165.5)^{b}$ & $396.6(30.0)$ & $4.2(0.3)$ & nq & 8401.9 \\
\hline 8 & $28.3(0.5)$ & $5110.6(24.7)^{b}$ & $153.0(1.0)$ & $2.6(0.0)$ & nq & 5294.5 \\
\hline 9 & $335.3(16.9)$ & $6104.4(6.3)^{b}$ & $548.8(108.8)$ & $3.3(0.2)$ & $3.0(0.8)$ & 6994.8 \\
\hline 10 & $228.7(9.8)$ & $1090.8(18.5)^{b}$ & $2048.8(66.5)$ & $0.5(0.1)$ & $5.8(0.2)$ & 3374.7 \\
\hline 11 & $149.4(0.4)$ & $1700.5(18.4)^{b}$ & $3245.9(15.9)$ & $1.0(0.0)$ & $4.2(0.0)$ & 5101.0 \\
\hline
\end{tabular}

\footnotetext{
${ }^{a}$ Results are expressed as mean (standard deviation) of three determinations. nq, not quantified. ${ }^{b}$ Values represent the sum of ascorbic acid plus tartaric acid.
}

Mushroom browning results from the action of phenol oxidase on phenolic compounds, which are oxidized to quinones and form brown/black melanin pigments. In a previous work (35) the necessity of refrigeration to retard browning was shown. On the other hand, the loss of water also increased phenol oxidase activity. However, the drying process is the most widely used method to ensure long-term storage (9). As expected, dehydrated samples (samples 1-3) exhibited the same phenolic compounds (Table 2), corresponding to $\sim 15.5 \mathrm{mg} / \mathrm{kg}$. No significant differences in the phenolics profile were obtained 

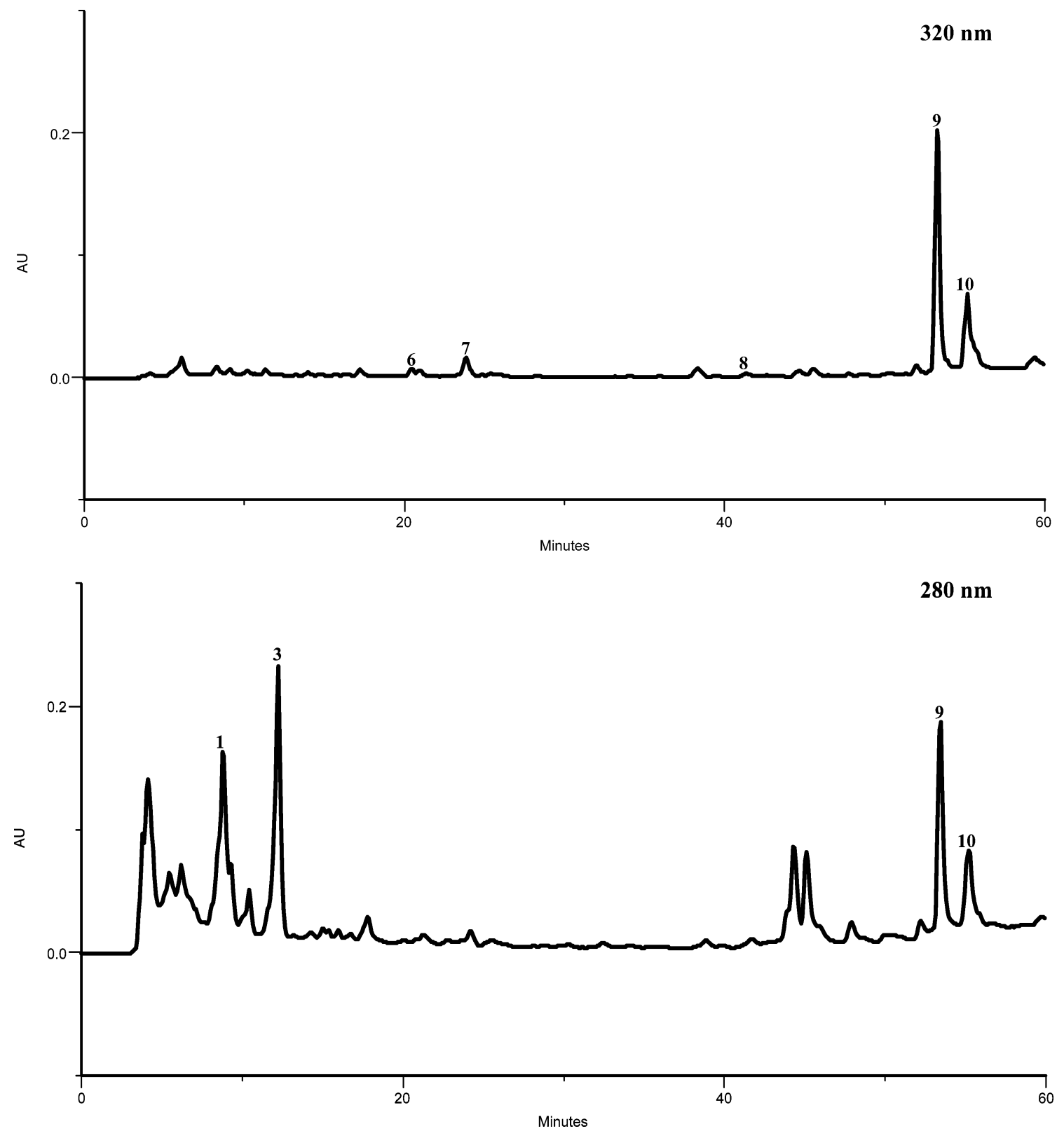

Figure 2. HPLC-DAD chromatogram of phenolic compounds in chanterelle (sample in olive oil). Peaks: (1) hydroxytyrosol; (3) tyrosol; (6) caffeic acid; (7) p-coumaric acid; (8) rutin; (9) luteolin; (10) apigenin.

with these samples, in which 3-O-caffeoylquinic acid was still the compound present in highest amounts, representing $61 \%$ of total identified phenolics (Figure 3).

Caffeoylquinic acids were not detected in the samples preserved in olive oil (samples 10 and 11), which may be explained by their degradation during boiling of the samples in the mixture of vinegar and water with salt. However, besides the presence of caffeic acid, $p$-coumaric acid, and rutin, these samples additionally exhibited another four phenolic compounds (Figure 2; Table 2): hydroxytyrosol, tyrosol, luteolin, and apigenin. The presence of these compounds in chanterelle may be attributed to the olive oil, because they were not found in frozen samples and they are reported to exist in olive oil (36, 37). Samples preserved in olive oil were those that, by far, exhibited the highest amounts of phenolic compounds ( $~ 900.4$ $\mathrm{mg} / \mathrm{kg}$ ) (Table 2). The phenolics profile of these samples is distinct from those of the frozen ones, presenting hydroxytyrosol and tyrosol as the major compounds (each corresponding to $\sim 44 \%$ ) (Figure 3). Despite the presence of these two com- pounds and luteolin and apigenin, no significant differences were found for caffeic acid, p-coumaric acid, and rutin, when compared with frozen samples.

Samples preserved in wine vinegar (samples 7-9) exhibited the same phenolics detected in frozen samples, with the exception of 3-O-caffeoylquinic acid, probably lost during boiling. Additionaly, 4- and 5-O-caffeoylquinic, caffeic, and $p$-coumaric acids existed in trace amounts (Figure 3; Table 2). These samples also presented hydroxytyrosol and tyrosol (Table 2), which may be provided by the vinegar, as they are described to occur in this matrix $(38,39)$. The phenolic profile of these samples is different from the previous ones, exhibiting hydroxytyrosol as the major compound ( $\sim 86 \%$ of total identified phenolics) (Figure 3), which is mainly responsible for the high contents of phenolic compounds ( $~ 339.4 \mathrm{mg} / \mathrm{kg}$ ).

Organic Acids. Organic acids are known to have a lower susceptibility to change during processing and storage than other components such as pigments and flavor compounds (40). The HPLC-UV analysis showed that all of the samples presented a 
Dehydrated

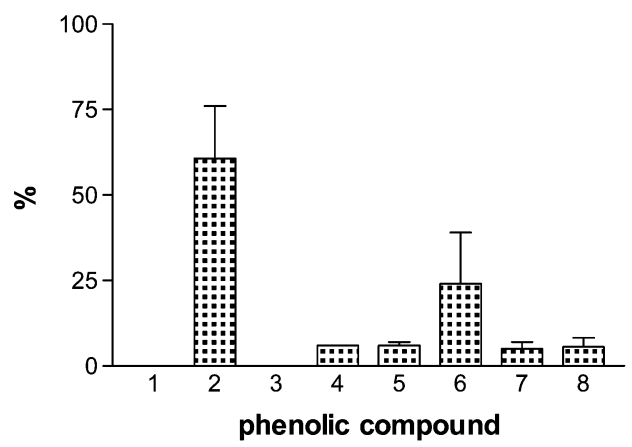

Vinegar

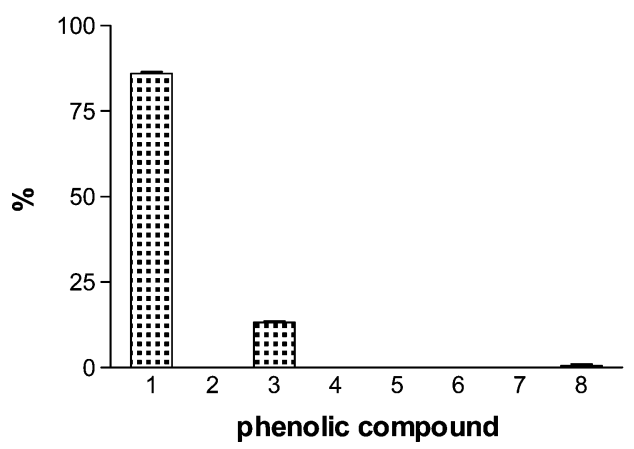

Frozen

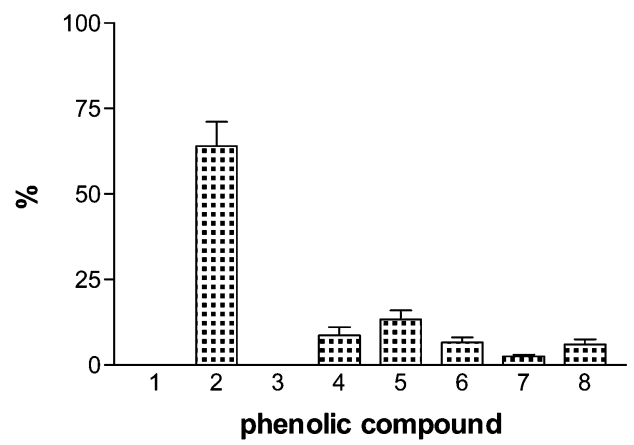

Olive oil

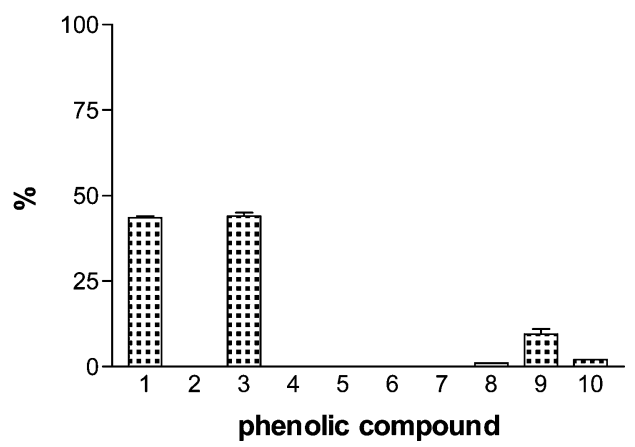

Figure 3. Phenolics profile of chanterelle preserved under four procedures. Values represent mean, and standard error bars are on the top of each column. (1) Hydroxytyrosol; (2) 3-O-caffeoylquinic acid; (3) tyrosol; (4) 4-O-caffeoylquinic acid; (5) 5-O-caffeoylquinic acid; (6) caffeic acid; (7) p-coumaric acid; (8) rutin; (9) luteolin; (10) apigenin.

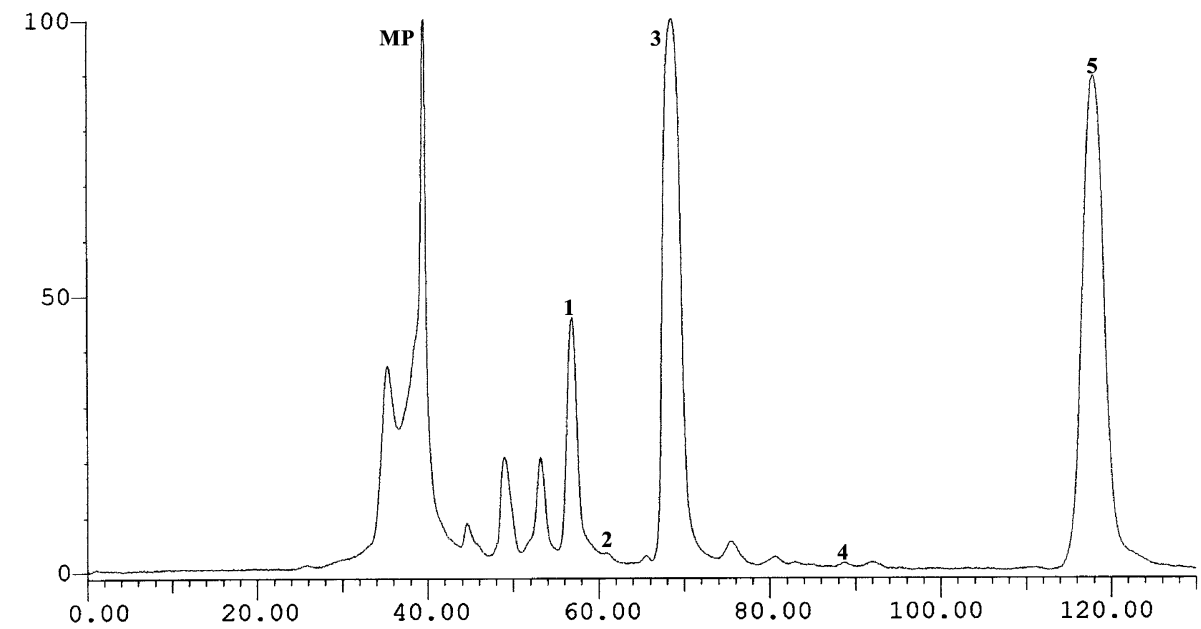

Figure 4. HPLC-UV chromatogram of organic acids in chanterelle (frozen sample). Detection was at $214 \mathrm{~nm}$. Peaks: (MP) mobile phase; (1) citric acid; (2) ascorbic acid; (3) malic acid; (4) shikimic acid; (5) fumaric acid.

profile composed of at least five organic acids: citric, ascorbic, malic, shikimic, and fumaric acids (Figure 4; Table 3). Samples preserved in vinegar and in olive oil also exhibited tartaric acid, which coeluted with ascorbic acid.

The quantification of the identified compounds in chanterelle frozen samples (samples 4-6) ranged from 5 to $8 \mathrm{~g} / \mathrm{kg}$ (Table 3), with malic acid, followed by citric acid, as the main compounds, corresponding to 85 and $15 \%$ of total compounds, respectively. Shikimic acid was present in very small amounts, below $0.1 \%$ of the total quantified compounds (Figure 5; Table 3).

The qualitative composition of dehydrated samples (samples 1-3) was similar to that of the frozen ones. Differences were noted at a quantitative level: in dehydrated samples the sum of the identified acids was lower $(\sim 3 \mathrm{~g} / \mathrm{kg}$ ) (Table 3), with malic acid as the major compound, although it represented only $78 \%$ of total identified acids. In addition, the amount of ascorbic acid was noticeably higher ( $\sim 6 \%$ of total acids) (Figure 5; Table 3).

The quantification of the identified organic acids in the samples preserved in vinegar (samples 7-9) also ranged from 5 to $8 \mathrm{~g} / \mathrm{kg}$ (Table 3). Under the analytical conditions used, ascorbic acid coeluted with tartaric acid, which was also found in the samples and came from the vinegar, as it is a very important compound in that matrix (41). Therefore, those two organic acids exhibited the highest content ( $\sim 92 \%$ of total compounds), significantly higher than the amount of ascorbic acid in frozen samples (Figure 5; Table 3). Malic acid, which was the main compound in the frozen samples, was present in significantly lower levels $(\sim 5 \%)$. 
Dehydrated

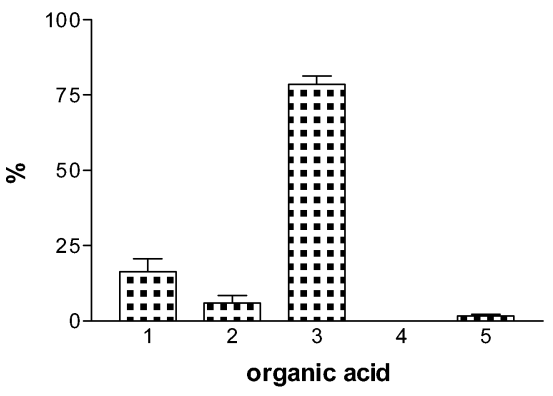

Vinegar

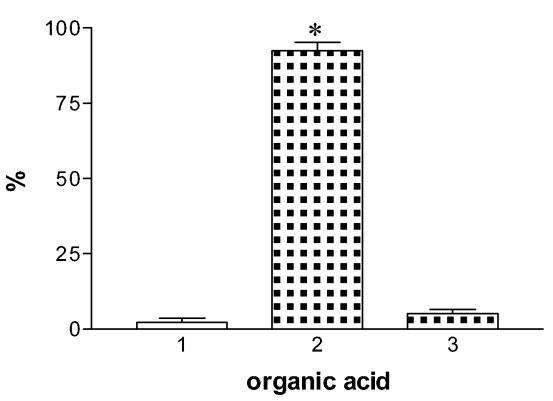

Frozen

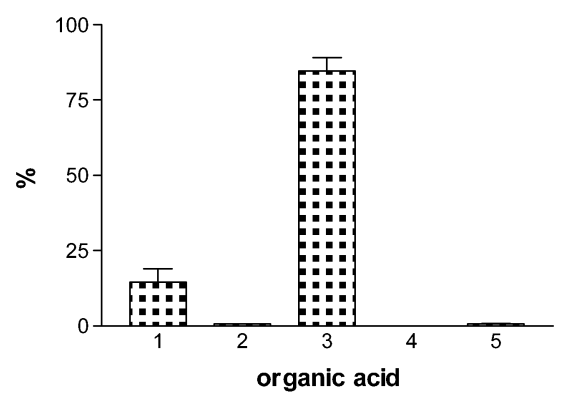

Olive oil

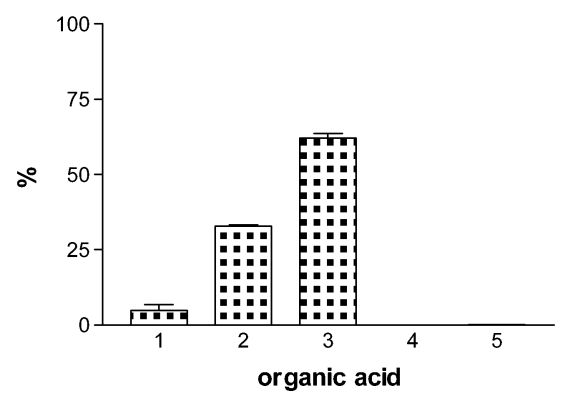

Figure 5. Organic acids profile of chanterelle preserved under four procedures. Values represent mean, and standard error bars are on the top of each column. (1) Citric acid; (2) ascorbic acid; (3) malic acid; (4) shikimic acid; (5) fumaric acid; (*) ascorbic plus tartaric acid.

The same observations were found for the samples preserved in olive oil (samples 10 and 11): when compared with the frozen samples, a significant increase in the contents of ascorbic acid and a significant decrease in malic acid amounts (ca. 33 and $62 \%$ of total acids, respectively) were noted (Figure 5; Table 3). Because these samples were also treated with vinegar, the rise of ascorbic acid (although not so high has that found for the samples preserved in vinegar) could be due to the existence of tartaric acid in the samples, as previously mentioned.

As far as we know, this is the first report concerning the phenolic compounds and organic acids composition of chanterelle mushroom. The work herein indicates that the preservation in olive oil and in vinegar affects the chemical composition of this species, which may be important when nutritional and health aspects are considered. However, the existence of chemical variability within the species cannot be excluded considering that, as each individual results from the cross-breeding of different hyphas, each mushroom presents a distinct genotype. Additionally, more samples should be analyzed, to clearly establish the influence of the conservation procedure on the phenolics and organic acids profiles of chanterelle.

\section{LITERATURE CITED}

(1) Kalac, P.; Svoboda, L. A review of trace element concentrations in edible mushrooms. Food Chem. 2000, 69, 273-281.

(2) Alonso, J.; García, M. A.; Pérez-López, M.; Melgar, M. J. The concentrations and bioconcentration factors of copper and zinc in edible mushrooms. Arch. Environ. Contam. Toxicol. 2003, 44, 180-188.

(3) Agrahar-Murugkar, D.; Subbulakshmi, G. Nutritional value of edible wild mushrooms collected from the Khasi hills of Meghalaya. Food Chem. 2005, 89, 599-603.

(4) Vaughan, J. G.; Geissler, C. A. In The New Oxford Book of Food Plants; Oxford University Press: New York, 1997; p 196.

(5) Mdachi, S. J. M.; Nkunya, M. H. H.; Nyigo, V. A.; Urasa, I. T. Amino acid composition of some Tanzanian wild mushrooms. Food Chem. 2004, 86, 179-182.
(6) Mattila, P.; Suonpää, K.; Piironen, V. Functional properties of edible mushrooms. Nutrition 2000, 16, 694-696.

(7) Manzi, P.; Gambelli, L.; Marconi, S.; Vivanti, V.; Pizzoferrato, L. Nutrients in edible mushrooms: an inter-species comparative study. Food Chem. 1999, 65, 477-482.

(8) Mattila, P.; Salo-Väänänen, P.; Könkö, K.; Aro, H.; Jalava, T. Basic composition and amino acid contents of mushrooms cultivated in Finland. J. Agric. Food Chem. 2002, 50, 64196422.

(9) Manzi, P.; Marconi, S.; Aguzzi, A.; Pizzoferrato, L. Commercial mushrooms: nutritional quality and effect of cooking. Food Chem. 2004, 84, 201-206.

(10) Rangel-Castro, J. I.; Staffas, A.; Danell, E. The ergocalciferol content of dried pigmented and albino Cantharellus cibarius fruit bodies. Mycol. Res. 2002, 106, 70-73.

(11) Mattila, P.; Piironen, V. I.; Uusi-Rauva, E. J.; Koivistoinen, P. E. Vitamin D contents in edible mushrooms. J. Agric. Food Chem. 1994, 42, 2449-2453.

(12) Vetter, J. Chemical composition of eight edible mushrooms. Z. Lebensm. Unters. Forsch. 1993, 196, 224-227.

(13) Sudhakara Reddy, M.; Babita, K.; Gay, G.; Ramamurthy, V. Influence of aluminium on mineral nutrition of the ectomycorrhizal fungi Pisolithus sp. and Cantharellus cibarius. Water, Air, Soil Pollut. 2002, 135, 55-64.

(14) Jennemann, R.; Geyer, R.; Sandhoff, R.; Gschwind, R. M.; Levery, S. B.; Grone, H. J.; Wiegandt, H. Glycoinositolphosphosphingolipids (basidiolipids) of higher mushrooms. Eur. J. Biochem. 2001, 268, 1190-1205.

(15) Wang, H. X.; Ngai, H. K.; Ng, T. B. A ubiquitin-like peptide with ribonuclease activity against various polyhomoribonucleotides from the yellow mushroom Cantharellus cibarius. Peptides 2003, 24, 509-513.

(16) Ng, T. B.; Wang, H. X. A homodimeric laccase with unique characteristics from the yellow mushroom Cantharellus cibarius. Biochem. Biophys. Res. Commun. 2004, 313, 37-41.

(17) Rangel-Castro, J. I.; Danell, E.; Taylor, A. F. S. Use of different nitrogen sources by the edible ectomycorrhizal mushroom Cantharellus cibarius. Mycorrhiza 2002, 12, 131-137. 
(18) Stadler, M.; Sterner, O. Production of bioactive secondary metabolites in the fruit bodies of macrofungi as a response to injury. Phytochemistry 1998, 49, 1013-1019.

(19) Anke, H.; Morales, P.; Sterner, O. Assays of the biological activities of two fatty acid derivatives formed in the edible mushrooms Cantharellus cibarius and C. tubaeformis as a response to injury. Planta Med. 1996, 62, 181-183.

(20) Grüter, A.; Friederich, U.; Würgler, F. E. The mutagenicity of edible mushrooms in a histidine-independent bacterial test system. Food Chem. Toxicol. 1991, 29, 159-165.

(21) Mier, N.; Canete, S.; Klaebe, A.; Chavant, L.; Fournier, D. Insecticidal properties of mushroom and toadstool carpophores. Phytochemistry 1996, 41, 1293-1299.

(22) Silva, B. M.; Andrade, P. B.; Valentão, P.; Ferreres, F.; Seabra, R. M.; Ferreira, M. A. Quince (Cydonia oblonga Miller) fruit (pulp, peel, and seed) and jam: antioxidant activity. J. Agric. Food Chem. 2004, 52, 4705-4712.

(23) Bas, C.; Kuyper, T. H. W.; Noordeloos, M. E.; Vellinga, E. C. In Flora Agaricina Neerlandica: Critical Monographs on Families of Agarics and Boleti Occurring in The Netherlands; Balkema: Rotterdam, The Netherlands, 1990-2001; Vol. 1-5.

(24) Bon, M. In Guia de Campo de los Hongos de Europa; Ediciones Omega: Barcelona, Spain, 1988.

(25) Courtecuisse, R.; Duhem, B. In Mushrooms and Toadstools of Britain and Europe; HarperCollins Publishers: London, U.K., 1995.

(26) Courtecuisse, R. In Mushrooms of Britain and Europe; HarperCollins Publishers: London, U.K., 1999.

(27) Marchand, A. In Champignons du Nord et du Midi; Soc. Mycol. Pyrénées Mediterranéenes: Perpignan, France, 1971-1986; Vol. $1-9$.

(28) Moser, M. In Keys to Agarics and Boleti (Polyporales, Boletales, Agaricales, Russulales); Roger Phillips: London, U.K., 1983.

(29) Silva, B. M.; Andrade, P. B.; Mendes, G. C.; Seabra, R. M.; Ferreira, M. A. Study of the organic acids composition of quince (Cydonia oblonga Miller) fruit and jam. J. Agric. Food Chem. 2002, 50, 2313-2317.

(30) Andrade, P. B.; Carvalho, A. R. F.; Seabra, R. M.; Ferreira, M. A. A previous study of phenolic profiles of quince, pear, and apple purees by HPLC diode array detection for the evaluation of quince puree genuineness. J. Agric. Food Chem. 1998, 46, 968-972.

(31) Silva, B. M.; Andrade, P. B.; Mendes, G. C.; Valentão, P.; Seabra, R. M.; Ferreira, M. A. Analysis of phenolic compounds in the evaluation of commercial quince jam authenticity. J. Agric. Food Chem. 2000, 48, 2853-2857.
(32) Silva, B. M.; Andrade, P. B.; Seabra, R. M.; Ferreira, M. A. Determination of selected phenolic compounds in quince jams by solid-phase extraction and HPLC. J. Liq. Chromatogr. Relat. Technol. 2001, 24 (18), 2861-2872.

(33) Silva, B. M.; Andrade, P. B.; Valentão, P.; Mendes, G. C.; Seabra, R. M.; Ferreira, M. A. Phenolic profile in the evaluation of commercial quince jellies authenticity. Food Chem. 2000, 71, 281-285.

(34) Silva, B. M.; Andrade, P. B.; Ferreres, F.; Domingue, A. L.; Seabra, R. M.; Ferreira, M. A. Phenolic profile of quince fruit (Cydonia oblonga Miller) (pulp and peel). J. Agric. Food Chem. 2002, 50, 4615-4618.

(35) Rajarathnam, S.; Shashirekha, M. N.; Rashmi, S. Biochemical changes associated with mushroom browning in Agaricus bisporus (Lange) Imbach and Pleurotus florida (Block \& Tsao): commercial implications. J. Sci. Food Agric. 2003, 83, $1531-1537$.

(36) Servili, M.; Baldioli, M.; Selvaggini, R.; Miniati, E., Macchioni, A.; Montedoro, G. High-performance liquid chromatograpgy evaluation of phenols in olive fruit, virgin olive oil, vegetation waters and pomace and 1D- and 2D-nuclear magnetic resonance characterization. J. Am. Oil Chem. Soc. 1999, 76, 873-882.

(37) Brenes, M.; Garcia, A.; García, P.; Rios, J. J.; Garrido, A. Phenolic compounds in spanish olive oils. J. Agric. Food Chem. 1999, 47, 3535-3540.

(38) Morales, M. L.; Tesfaye, W.; García-Parrilla, M. C.; Casas, J. A.; Troncoso, A. M. Sherry wine vinegar: physicochemical changes during the acetification process. J. Sci. Food Agric. 2001, $81,611-619$.

(39) García-Parrilla, M. C.; Heredia, F. J.; Troncoso, A. M. Sherry wine vinegars: phenolic composition changes during aging. Food Res. Int. 1999, 32, 433-440.

(40) Cámara, M. M.; Díez, C.; Torija, M. E.; Cano, M. P. HPLC determination of organic acids in pineapple juices and nectars. Z. Lebensm.-Unters.-Forsch. 1994, 198, 52-56.

(41) Sáiz-Abajo, M. J.; González-Sáiz, J. M.; Pizarro, C. Multiobjective optimisation strategy based on desirability functions used for chromatographic separation and quantification of L-proline and organic acids in vinegar. Anal. Chim. Acta 2005, in press.

Received for review January 18, 2005. Revised manuscript received March 30, 2005. Accepted March 31, 2005.

JF0580263 